\title{
God was with us in the OR that day
}

Monica Soni ${ }^{1}$

${ }^{1}$ Georgetown University School of Medicine

Keywords: patient encounter, faith, clinical reflection

https://doi.org/10.52504/001c.25144

\section{Georgetown Medical Review}

Vol. 5, Issue 1, 2021

It was the last day of my general surgery rotation and all appeared relatively quiet. I signed up for a sacral wound debridement case, after which I planned to help out on the floor as no other cases were scheduled for the day.

As we were prepping the operating room (OR) for the debridement, I heard whispers about an emergent case: an elderly female with rectal bleeding had been brought in by ambulance earlier that morning. She had undergone an immediate colonoscopy, which revealed a perforation in her sigmoid colon.

I walked over to the gastrointestinal (GI) suite to investigate as a congregation quickly formed around the patient, comprised of the colorectal surgeon and his team, the chief surgical resident, the OR nurse, the anesthesiologist, the medical technician, and the gastroenterologist. As an outside observer, it was controlled, simultaneous chaos: forms were being signed, information was being shared by hushed, hurried voices, and all the while vitals were being measured. I felt nervous given the emergent nature of the case, but also excitement. My previously uneventful day was about to become far more interesting, but it was more than that-it was the opportunity to battle disease, and the clock, in real time.

Suddenly, all the noise and movement was punctuated by a distinct ring-it was the GI suite's main line. One of the nurses answered and I could hear her repeat "Cherrydale Baptist." It was the patient's pastor calling, and he was hoping to speak with her urgently. We couldn't bring the patient to the landline easily, so I volunteered to call him back on my cell phone. It was the only way I could be helpful in the moment.

As I entered Bay 12, I introduced myself to the patient and explained that her pastor would like to speak with her. We quickly got him on the phone and I soon found myself in the middle of prayer. I held my patient's hand. We closed our eyes. And we prayed-for the skill of the surgeon, for the fact that her condition was recognized early, for everyone looking after her, for her safe recovery. She had the sweetest, most grandmotherly of voices, and she reminded me of my own beloved Grammy who had passed away just weeks earlier-my eyes began to well with tears. 
I can't say I am terribly religious. But as the daughter of a Lutheran, the granddaughter of a Hindu, and a forever student of the Jesuits, the power of the moment was not lost on me. The call maybe lasted a minute, but all felt calm during those sixty seconds. I clutched the sticky note with her pastor's phone number scribbled on it, determined to keep it safe.

As soon as the call ended, we whisked the patient to the OR. With the precision of an orchestra and the efficiency of a NASCAR pit crew, the patient was prepped for surgery. An open incision was made in the abdomen and, amid blood and feculent material, a perforation the size of a quarter was quickly identified. The surgeon paused to acknowledge the seriousness of it all: there was a strong possibility the patient would become very sick over the next several hours to days, with a risk of mortality as high as thirty percent. But I couldn't help but feel that things were going to be okay-after all, God was with us in the OR that day.

My rotation ended and I unfortunately lost track of my patient. But I think of her often and hold this encounter among the most meaningful interactions of my third year.

Here is to hoping — and praying — that she is recovering well and will be able to return to Cherrydale Baptist in due time.

Ad maiorem Dei gloriam. 